Для цитирования: Борисов С.В. Гредновская Е.В., Динабург С.Р Философская практика: лето - осень 2017

(по материалам российских семинаров с международным участием) / Социум и власть. 2017. № 6 (68). С. 131-137.

удК 101

ФИЛОСОФСКАЯ

ПРАКТИКА: ЛЕТО-ОСЕНЬ 2017 (ПО МАТЕРИАЛАМ РОССИЙСКИХ СЕМИНАРОВ С МЕЖДУНАРОДНЫМ УЧАСТИЕМ) ${ }^{1}$

\author{
Борисов Сергей Валентинович \\ Южно-Уральский государственный \\ гуманитарно-педагогический университет, \\ заведующий кафедрой философии \\ и культурологии, \\ доктор философских наук, профессор, \\ Челябинск, Россия. \\ E-mail: borisovsv69@mail.ru
}

Гредновская Елена Васильевна,

Южно-Уральский государственный университет

(Национальный исследовательский университет)

заведующая кафедрой философии, кандидат философских наук, доцент, Челябинск, Россия. E-mail: nebytiya_net@mail.ru

Динабург Светлана Роальдовна

Пермский национальный исследовательский политехнический университет, старший преподаватель кафедрь философии и права, Пермь, Россия.

E-mail:solo.alias@list.ru

Аннотация

В статье дается обзор основных идей философской практики как направления современной философии на основе анализа материалов серии семинаров, проходивших в России в период лета-осени 2017 г.

Ключевые понятия: современная философия философская практика, философское консультирование, глубинная философия, философские сообщества.
Летом и осенью 2017 года в нашей стране прошла серия семинаров по философской практике, которые можно считать плодотворным началом консолидации фи лософов-практиков России и укрепления международного сотрудничества в этой области. Инициаторами и организаторами состоявшихся семинаров выступили кафедра философии Южно-Уральского государственного университета и кафедра философии и культурологии Южно-Уральского гуманитарно-педагогического университета. Семинары проходили в нескольких регионах России: Республике Крым, Среднем и Южном Урале, Санкт-Петербурге. Помимо содержательной части, семинары представляли собой одну из форм образовательного и научного туризма, знакомства иностранных гостей с Россией.

Какие же главные идеи объединяли участников семинаров? Прежде всего, уверенность в том, что самым актуальным вопросом современной философии является вопрос о практическом использовании ее громадного потенциала. Хотя философия существует давно, философская практика - это новый и весьма эффективный способ использования философствования для решения многих повседневных и глобальных проблем, с которыми сталкивается современный человек, так как в основе всех этих проблем, по большому счету, лежат проблемы мировоззрения. По своей сути философская практика - это возвращение философии к своему первоначальному статусу, который она имела в античной культуре. И в этом контексте философия - это не теории, не догмы и не системы знаний как дань науке, а набор упражнений для душевной, интеллектуальной и эмоциональной «заботы о себе».

Философская практика начала институализироваться сравнительно недавно в 80-90 годы прошлого века. Это неудивительно, так как именно на рубеже веков возникла необходимость сбросить с философии маску "научности», которая прочно приросла к ней, но никогда не была ей органична. У философской практики, как нового направления, появились свои «сократы»и свои «протагоры», и даже наметились некоторые "схоластические» разногласия, но эти институциональные аспекты вовсе не мешают реализовывать главную миссию этого

${ }^{1}$ Статья подготовлена в рамках задания № 35.5758.2017/БЧ «Философская практика как новая парадигма современных социогуманитарных исследований» Министерства образования и науки Российской Федерации на выполнение государственных работ в сфере научной деятельности и проекта РФФИ № 17-33-00021 «Теория и практика философского консультирования: компаративистский подход. 
интеллектуального движения - сделать философию эффективным средством для достижения осознанной и счастливой жизни. В отличие от новых религий, пугающих своей фанатичной одержимостью, социально порабощающих и жонглирующих квазинаучной терминологией, философская практика не имеет ни «гуру», ни «церквей», не прикрывается наукой и не занимается проповеднической деятельностью. Автономия личности, которая творит идеи собственной жизни, личности, которая хочет быть услышанной и которой предоставляется такая возможность, - вот главные условия философской практики. Философия рано или поздно должна была освободиться от роли «служанки» религии, идеологии или науки и стать практическим делом каждого человека. Это и происходит.

Однако «выйдя на улицу», философская практика не теряет связи с академической средой, подчеркивает челябинский философ Е.В. Гредновская. Практикующих философов интересуют современные образовательные стратегии, большинство из них продолжают сотрудничать с учебными заведениями, ведут преподавательскую деятельность, проводят сессии и мастерклассы, используя ресурс философского партнерства, философского диалога и философского консультирования. И такая установка современного этапа развития философской практики отвечает запросам современности: необходимости преодоления расщепленности субъекта между «миром приватным» и «миром публичным».

Так что же такое «философская практика»? Каковы ее место и роль в российской культурном пространстве? Поискам ответа на эти вопросы были посвящены данные семинары, которым предшествовала большая подготовительная работа. В итоге участникам была предложена весьма насыщенная содержательная программа. В работе семинаров приняли участие философы и психологи из Москвы, Санкт-Петербурга, Волгограда, Минска, Екатеринбурга, Челябинска, Перми, Севастополя, а также зарубежные гости из США, Франции, Италии и Израиля.

Итогом данной работы стала идея создания Российской общественной организации «Российская ассоциация философов-практиков». Это будет общественное объединение, которое действует по принципу равноправия ее членов, гласности и открытости. Ассоциация будет активно сотрудничать со всеми заинтересованными лицами и организациями, разделяющи- ми и пропагандирующими идеи философской практики. Члены ассоциации будут объединяться как по научным интересам, так и по личностным мировоззренческим предпочтениям, открывающим возможность диалога и обмена идеями. Ассоциация обеспечит всем желающим свободный доступ к различным информационным и поисковым системам, связанным с движением философской практики, будет координировать творческую деятельность ее членов по разработке форм и методов философской практики, популяризировать и пропагандировать философские знания, навыки философской практики и философский образ жизни в целом.

Наш замысел заключается в том, чтобы не только ученые, но и широкая общественность проявила внимание к движению философской практики, чтобы каждый человек нашел в ней свое место в соответствии со своими предпочтениями, интересами, мировоззренческими принципами, расширив для себя сферу духовной деятельности. Мы планируем делиться опытом работы с международными организациями философской практики, организовывать совместные научные и образовательные мероприятия и проекты. Ассоциация создаст условия для открытого, свободного общения философов-практиков между собой, с представителями других областей знаний. Любой, кто желает реализовать себя в этой области, получит необходимые консультации, для него будет открыт свободный доступ для участия в работе конференций, семинаров и круглых столов, образовательных проектов и обучающих программ для детей и взрослых, а также философских клубов, кафе и других объединений по интересам.

Итак, какие же главные ключевые темы обсуждались на наших семинарах. Первая тема: «Философская практика и психотерапия: общее и особенное». Участниками семинаров осуществлялся поиск теоретических оснований, позволяющих разрабатывать концепт философской практики. Философом и психологом из Перми С.Р. Динабург было отмечено, что прояснение содержания общего и особенного исследуемых феноменов не исчерпывается выявлением их сходства и различий, но требует рассмотрения более широкого культурного контекста и учета динамики современной реальности, характеризуемой через аспекты изменчивости и неопределенности. Для обоснования принципиальных трудностей, которые возникают при философском ана- 
лизе любой практики средствами понятийной экспликации, затрагивались идеи так называемой «теории практик» (общего стиля исследований в русле прагматического поворота), и в частности концепции «фоновых практик». Подчеркивалось, что схватывание содержания практики также является практикой, осуществляемой по мере овладения деятельностным контекстом (процедурами, соглашениями, допущениями и пр.), существующими в поле практики. Идея сопоставления философской практики с психотерапией ценна не только в силу их сходства («забота о себе» (С.В. Борисов), «направленность на трансформацию» (Р. Лахав)), благодаря чему можно обнаружить их общую традицию, онтологический базис, подобрать родовое понятие или «апофатическое» определение через противопоставление, но также и потому, что значимый «фон» практики, ее суть, можно различить именно благодаря «визуальному» контрасту. Психотерапия, в основе которой лежат особые отношения между клиентом и терапевтом, организованная как профессия, обладающая своим хронотопом, этосом и правилами коммуникации, позволяет проявить то, что в философской практике реализуется иначе, или содержится потенциально.

Челябинский философ С.В. Борисов в русле этой проблематики предложил несколько концептуальных поворотов при обращении к основаниям, корням философской практики и психотерапии. Первый поворот заключается в некотором отходе от теорий и методов и возвращении внимания к самому человеку. Второй поворот в трактовке проблемы человека, в смещении акцента от «сущего» к «бытию», поэтому классический кантовский вопрос понимается как проблема, и даже основной вопрос философии - «как быть» или «что значит быть человеком»? Эта проблема раскрывается через столкновение с подлинностью бытия в его экзистенциальном смысле. Подлинность открывается человеку или накатывает на него таким образом, что человек не может противопоставить этому обычные схемы самосознания или поведения, не может укрыться в убежище повседневности. Продолжая традицию от Канта через Кьеркегора и Гуссерля, мы приходим к пониманию так называемых «философских болезней» (А. Хольцхей-Кунц), представляющих собой особую чувствительность к бытию. Тогда пространство «работы с болезнями» разделяется не институционально, на философскую практику и психотерапию, а открывает возможности движения к подлинности путем признания «философской болезни» как факта, путем ее переживания, признания ее истин (часто несовместимых с обыденной или научной установкой).

Многие участники семинаров отмечали, что имеются все основания полагать, что философия глубоко укоренена в природе человека, для него неудивительно быть философом, удивительно не быть им, т.е. не размышлять о сущности вещей. Наиболее ярко представил эту мысль волгоградский философ Н.В. Омельченко, отмечая, что многие утрачивают эту способность. Упакованные в стандарты современного социума люди лишаются радости живого мышления. Благодаря философской рефлексии человек выходит за пределы ограниченного жизненного круга, трансцендирует себя за пределы повседневности. Терапевтический эффект обеспечивается именно этим переходом человека в метафизическую реальность, в мир сущностных отношений. На основании этого можно говорить о философской терапии. Сущность человека (логос, дух, душа) есть совокупность (внутренних и внешних) устойчивых универсальных отношений индивида с миром. В определенном смысле можно сказать, что душа человека есть энтелехия бесконечного универсума, она есть микрокосм и потому не может быть всецело детерминирована социальными процессами и структурами. Философская терапия может включать вопрошание о жизни и мире, но не должна сводиться к психоанализу или какой-либо психотерапии. Суть философской терапии - в размышлении о сущности бытия. Конечно, философское размышление может начинаться с любого дискурса, задача же философа-консультанта двигаться в сторону сущности обсуждаемого предмета, субъективный дух должен «подключиться» к объективному духу. При этом человек сам должен трансцендировать себя к объективной сущности бытия.

Для участников семинаров актуальной темой была сама возможность обобщения и классификации многообразия форм и методов философской практики. В рамках этой проблематики было предложено много интересных идей. Например, челябинский философ В.И. Гладышев предложил объединить в единое целое новый формат философской практики - «философское партнерство» Р. Лахава, основные идеи концепции глубинного общения Г.С. Батищева, а также свою авторскую концепцию компенсаторного общения. Базовые концепты, реализующиеся в деятельности философского 
партнерства: единение, глубина понимания, резонирование и др., представляют собой особого вида творчество, выводящее личность за пределы повседневного общения. Общение, осуществляющееся в ходе философского партнерства, имеет компенсаторное значение, но не в форме адаптивной активности, а как активность неадаптивная (гетеростазис), тяготеющая к сверхкомпенсаторному общению. Последнее выводит партнеров по общению на более высокий уровень духовной целостности, взаимоутверждения, вместо эгоистического самоутверждения, единения, глубины взаимопонимания. Для этого весьма продуктивно использовать в опыте философского партнерства тексты художественных произведений. Здесь особое значение приобретает эмоциональная составляющая произведений. Именно она позволяет подключить психологические механизмы сопереживания, эмоциональные ресурсы личности, обеспечивающие глубокое понимание проблем, и будет с большей полнотой выражать возникшие в ходе философского партнерства внутренние отношения.

Челябинским философом К.Е. Резвушкиным была предложена ориентировочная типология подходов, используемых в современной философской практике, согласно которой все ее многочисленные течения можно условно разделить на два концептуальных подхода: 1) «терапевтический» и 2) «развивающий». Многие участники семинаров делились своим опытом, опираясь на данную бинарную типологию. В первом варианте активная позиция - у передающего знания, которого можно отождествить с мудрецом, что дает возможность трактовать данный подход как нефилософский, если исходить из того, что философия - это любовь к мудрости; также предполагается актуализация глубокого чувственно-эмоционального слоя клиента и помощь в решении какой-либо его экзистенциальной проблемы. Во втором варианте философ и клиент - уже «полные сосуды», философ не «передает» мысль, а помогает ей родиться (майевтика); активную позицию в данном случае занимает клиент, который задает проблематику, и чье мышление актуализируется в логическом и волевом аспектах. В ходе многочисленных дискуссий было выведено, что исходными «точками отсчета» для философа-практика могут быть следующие: а) человек изначально здоров, и необходимо работать с ним как со здоровым - это развивающий подход (позиция волгоградского философа
А.И. Макарова), б) человек всегда травмирован (в частности, системой школьного обучения), с ним необходимо работать как с травмированным - это терапевтический подход (позиция челябинского философа Е.В. Гредновской). С одной стороны, оба подхода могут быть использованы в работе с одним и тем же клиентом на разных этапах его продвижения, даже в рамках одной сессии одним и тем же философом-практиком. С другой стороны, каждый философ обычно тяготеет к какому-то одному из упомянутых подходов.

Для всех участников семинаров незабываемое впечатление оставило общение с известным американским философом-практиком Р. Лахавом. Поскольку, действительно, легко заблудиться во множестве технических деталей всего того, что называется философской практикой, Лахав всегда призывал всегда держать в фокусе внимания то, что составляет ее суть. Важно, чтобы философия не «мимикрировала» под другие дисциплины и не застревала в прошлом. Для этого нужно определить некую отправную точку, исток философской практики. Необходимо всегда обращаться к своему конкретному опыту, к тем специфическим моментам, в которых философия захватывает нас, вдохновляет нас, позволяет смотреть на жизнь в иной перспективе. В качестве такого метода Лахав предложил практику философского партнерства. Она представляет собой группу партнеров, осуществляющих совместное философское созерцание тех или иных аспектов мировоззренческих проблем методом феноменологической редукции. Главное условие философского партнерства - глубокое сосредоточение на том «чистом» опыте, который можно получить исходя из медитативного состояния, выносящего «за скобки» все автоматизмы мысли и речи внешнего повседневного опыта. Концентрация на этом опыте осуществляется методом медленного чтения фрагментов тех или иных философских текстов, содержащих в себе законченные идеи по созерцаемой проблеме. Высказывание собственных идей осуществляется в унисон с прочитанным текстом, выделяются его главные понятия, из которых совместными усилиями группы конструируется общая «карта идей», дополняемая концептами или образами, возникающими в пространстве «чистого» опыта каждого участника группы. Данное философское партнерство - это не интеллектуальный клуб и не научное сообщество. Целью групповой работы является коллективная помощь в прояснении философских 
идей за счет совместных усилий, а не соревновательные процедуры интеллектуальных споров и научных диспутов. Работа членов группы напоминает действия музыкантов в едином оркестре, добивающихся созвучия, гармонии.

Еще одной важной темой семинаров была «Философская практика в образовании». В ходе ее обсуждения было высказано много продуктивных идей. Философ из Екатеринбурга Л.И. Забара отметила, что философская практика может существенно замедлить процесс эмоционального выгорания педагогов, поскольку снимает оппозицию «учитель - ученик» и акценти рует внимание не на методах «учета и контроля», а на формах конструктивного взаимодействия в ходе совместной проектной деятельности. Ее коллега, екатеринбургский философ О.А. Блинова, на примере сравни тельного анализа ведущих образовательных программ начального образования, требующих применения формально-логического мышления для их освоения, выявила, что ни одна из них не предполагает изучения даже минимальных основ формальной логики; этот пробел современной системы образования можно устранить при помощи философской практики как метода развития мышления на основе вопрошания. Минский философ Н.Е. Ильюшенко обратила внимание на то, что особенно продуктивной и востребованной формой развития философской практики сегодня можно считать курсы дистанционного обучения, размещенные в сети Интернет в открытом доступе, ориентированные на широкую аудиторию; реализация этих курсов позволит преодолеть барьеры постсоветской системы образования.

В ходе семинаров обсуждались также проблемы выработки оптимальных форм и методов философской практики в образовании. Челябинским философом Е.В. Гредновской были предложены следующие темы для обсуждения: 1) «Философская практика» как исходная научная база, где проводился анализ дихотомий: «философская практика» в широком понимании - как античная традиция, как практика «заботы о себе», и «философская практика»в узком понимании - как профессиональная деятельность современных, преимущественно западных, философов; «философская практика» как академическое знание и «философская практика» как отказ от академизма; «философская практика» как теория и методология, и «философская практика» как «чистая практика» или «мировоззренческая терапия». Обсуждались также другие темы, такие как: 2) «Философская практика» как расширение педагогической деятельности и 3) «Философская практика в образовании» как научное направление. По сути, данные темы затрагивают вопросы институциализации «философской практики» в разных сферах научной и культурной коммуникации.

Особый интерес у участников семи наров вызвало выступление израильского философа-практика Л. Амир, которая отметила, что если философское консультирование, или практика, должны быть, прежде всего, философскими, то лучший способ это понять - это не только знание философии, но и знание о том, какое значение имеет философия именно в вашей стране в академическом смысле. Амир практикует индивидуальный подход в занятиях философией в конкретной работе с клиентом. Философская практика в этом смысле есть движение от повседневного, конкретного, базирующегося на опыте и личном интересе, к абстрактному, которое, начиная с философов Греции, рассматривается как главное условие человеческого существования, и затем перенесение этого обратно в контекст повседневного конкретного опыта. Философ-практик начинает с конкретных проблем, которые предлагает ему клиент, и привносит в них иные проблемы из области абстрактного, чтобы определить в процессе консультирования самый важный философский концепт, который поможет лучше осознать исходные проблемы клиента. Поскольку философская практика - это творческая деятельность, побуждающая находить методы, не следует уповать на точный логический метод, который понятен для нового клиента и понятен вам, важен контекст вашей работы, к которому нужно всегда возвращаться, - это гармоничные отношения.

Еще одной актуальной темой семинаров была «Философская практика и медиапространство». Челябинским философом И.Р. Камалиевой было отмечено, что поскольку Интернет становится основным средством и площадкой для информационного продвижения и дальнейшей реализации научных идей, сама деятельность большинства философов-практиков и формирование имиджа философской практики в целом осуществляется посредством интернет-ресурсов. Поэтому очень важно: 1) определение внешней целевой аудитории, типология аудитории и категоризация подходов, ориентированных на тот или иной тип аудитории; 2) особенности вза- 
имодействия в сети Интернет в процессе реализации философской практики. В ходе работы круглых столов по данной проблематике говорилось также о необходимости формирования образа философа-практика в медийном пространстве, владеющего навыками коммуникации с интернет-аудиторией; необходимости медийного выражения философских идей в форме, доступной наибольшему числу заинтересованной аудитории; необходимости учитывать особенности распространения информации в сети Интернет и ее конкурентоспособность, например, качество видеоматериала, технологию продвижения информации для целевой аудитории и т.д.

Особого внимания заслуживают мастер-классы, которые проводит известный философ-практик из Франции О. Бренифье. В основу этой формы философской практики Бренифье положены принципы работы с внутренней и внешней речью. Как известно, внешняя речь человека не всегда соответствует тому, о чем он думает, более того, поскольку внешняя речь большей частью автоматична: во-первых, те или иные высказывания человека могут вообще не выражать никакой мысли, а целиком и полностью относиться к проявлениям его эмоционального состояния; во-вторых, зачастую человек прибегает к внешней речи с целью замаскировать, скрыть реальные мысли о себе, об окружающих или о ситуации, невольно вводя в заблуждение себя и других. Поэтому задачей философа-практика, как было ярко показано Бренифье, является «примирить» собеседника с его собственной речью, т.е. открыть для него рефлексивный план анализа своих речевых высказываний для обнаружения тех скрытых мыслей, которые маскирует внешняя речь. Данная философская практика оказалась весьма эффективной как для прояснения смысла понятий, используемых во внешней речи, так и для прояснения смысла проблем, возникающих в тех или иных ситуациях, мешающих человеку в решении определенных жизненных задач. Как демонстрирует ведущий мастер-класса О. Бренифье, разоблачая автоматизмы эмоций, речи и действий, человек получает возможность осознания периметра своей «платоновской пещеры», а также возможность выхода из нее на новый уровень как мышления, так и мировоззрения в целом.

Следует отметить разнообразие форм проведения лекций, мастер-классов, групповой и индивидуальной работы, представленной на семинарах. Например, мно- гие лекции, мастер-классы, медитативные упражнения проходили в живописных «зеленых аудиториях», на открытом воздухе, на большой поляне на склоне горы или на берегу озера. Неотъемлемой частью семинаров являются недельные ретриты, дающие возможность осуществлять философскую практику в малых группах методом погружения.

Подводя итоги реализации проекта распространения философской практики в России в виде сети семинаров, следует отметить, что мы только в начале пути. Наша общая задача - использовать проверенные и разрабатывать новые формы философской практики, которые были бы более сосредоточены на основных, универсальных жизненных проблемах, более проникнуты философской традицией и направлены на свойственную этой традиции цель - личностный рост и внутреннюю трансформацию. Многие великие философы на протяжении всей истории философии понимали, что философия может трансформировать жизнь, открывать для нас новые измерения и новые внутренние глубины. Как и они, мы считаем, что философия может помочь преобразовать человеческую жизнь, помочь выйти за пределы поверхностных и механических способов существования.

В заключение хочется привести выдержки из Манифеста глубинной философии, который был написан осенью этого года интернациональной группой философов, собравшихся на ретрит в Италии. Во многом этот Манифест может служить руководством и для российских философов-практиков:

1. Целью Глубинной философской практики является личностная трансформация - иными словами, пробуждение новых измерений человеческой жизни. Ее главная цель не просто нормализовать жизнь, решать личные проблемы, а прежде всего развивать новые формы самосознания, новые смыслы, открывать новые внутренние глубины, новые жизненные измерения.

2. Глубинная философская практика базируется на философии, а философия - это дискурс, в основе которого лежат главные идеи об универсальных и фундаментальных жизненных проблемах. Любая практика, которая не касается этих главных идей и фундаментальных жизненных проблем и которая просто остается на уровне личных проблем и конкретных фактов, не является философской в полной мере. Точно так же и логический анализ или критическое мышление сами по себе 
не являются философией, если не касаются главных идей об универсальных, фундаментальных жизненных проблемах.

3. Глубинная философская практика опирается на силу философских идей, чтобы воздействовать на жизнь и трансформировать ее. Философские идеи имеют отношение к жизни не потому что они могут решать повседневные проблемы, и не потому что они «прилагаются»к жизни либо могут ее анализировать, а потому что они имеют непосредственное отношение к жизни, вдохновляют и пробуждают ее. Глубинная философская практика - это не разновидность прикладной философии.

4. Подлинный философский дискурс тесно связан с историей философской мысли. Философы-практики не философствуют в полной мере, если игнорируют идеи предыдущих мыслителей, как будто до них ничего уже не было сказано.

5. Однако дискурс глубинной философской практики является творческим. Он не слепо заимствует в качестве готовых рецептов взгляды авторитетов, оставшихся в истории философии. Их взгляды - это отправные точки для открытого, творческого, личностного исследования. В этом смысле глубинная философская практика предполагает личностный диалог с мыслителями прошлого.

6. В глубинной философской практике мы фокусируемся на неожиданной встрече конкретной человеческой ситуации с абстрактными универсальными идеями. Таким образом, когда мы имеем дело с личностными переживаниями и проблемами, мы выходим за пределы своего конкретного состояния, своего особенного, открывая для себя более широкие горизонты человеческой жизни. И наоборот, когда мы работаем с философским текстом, мы не останавливаемся на теоретическом уровне абстрактных дискуссий, а входим в конкретную ситуацию конкретного человека, ориентируясь на его личностные проблемы, эмоции и поведение. Таким образом, философия становится творческим резонирующим диалогом между индивидуальными и общечеловеческими проблемами.

7. Глубинная философская практика предназначена для людей, которые стремятся к личностному росту и трансформации - и таких людей в современном мире очень много. Наша целевая аудитория это люди, которые хотят жить более полной и глубокой жизнью, а не люди, которые просто хотят решать личные проблемы или ищут интеллектуальные развлечения.
For citing: Borisov S.V.,

Grednovskaya E.V., Dinaburg S.R.

Philosophic practice: summer - autumn

2017 (following the proceedings of Russian seminars with international participation) // Socium i vlast. 2017. № 6 (68). P. 131-137.

UDC 101

\section{PHILOSOPHIC PRACTICE: SUMMER - AUTUMN 2017 (FOLLOWING THE PROCEEDINGS OF RUSSIAN SEMINARS WITH INTERNATIONAL PARTICIPATION)}

\section{Borisov Sergey Valentinovich,}

South Ural State University of Humanities and Education,

Head of the Department Chair of Philosophy and Cultural Studies,

Doctor of Philosophy, Professor,

Chelyabinsk, Russia.

E-mail: borisovsv69@mail.ru

\section{Grednovskaya Elena Vasilyevna,}

South Ural State University (National

Research University),

Head of the Department Chair of

Philosophy,

Cand.Sc. (Philosophy), Associate Professor,

Chelyabinsk, Russia.

E-mail: nebytiya_net@mail.ru

\section{Dinaburg Svetlana Roal'dovna,}

Perm National Research Polytechnic

University,

Senior Lecturer of the Department Chair of

Philosophy and Law,

Perm, Russia.

E-mail: solo.alias@list.ru

\section{Annotation}

The article presents the review of the main ideas of philosophic practice as a field of modern philosophy on the basis of analyzing proceedings of Russian seminars which took place in the summer-autumn period of 2017.

Key concepts:

modern philosophy,

philosophic practice,

philosophic counselling,

deep philosophy,

philosophic associations. 